\title{
A survey of layer-type pullet rearing in Switzerland
}

\section{B. HUBER-EICHER}

Federal Veterinary Office, Centre for Proper Housing of Poultry and Rabbits, Burgerweg 22, 3052 Zollikofen, Switzerland

Battery cages for laying birds were banned in Switzerland in 1981. Several new systems were developed in the years that followed, but to date only the deep litter and aviary systems have complied with both the regulations of the Swiss Animal Welfare Act and given satisfactory production results. The ways in which layer replacements are reared has been found to be crucial if they are to be able to cope optimally with the new aviary system. For this reason, the Federal Veterinary Office commissioned a survey to investigate how layer replacement pullets were reared in Switzerland. Sixty six out of a total of 155 farms that had facilities to rear 500 or more chicks at one time were visited between April and December 1997. Data were gathered on the type of housing system, management methods and the prevalence of feather pecking. The results of the survey are presented in a descriptive way and discussed in relation to the conditions during the laying period.

Keywords: Layers; chicks; rearing; housing system; management; feather pecking

\section{Introduction}

The Animal Welfare Act, on which the Swiss people voted in 1978, came into force in 1981. It laid down the minimum requirements for the proper housing of productive livestock so that the housing does not '. . interfere with their bodily functions or their behaviour, or overtax their capacity to adapt' (Article 1, Animal Welfare Regulations). The poultry section contains regulations that have made farreaching and enduring changes to the way in which laying birds are kept in Switzerland. The requirement for protected, darkened nest boxes, suitable perches for all birds, or slatted floors and a minimum of $800 \mathrm{~cm}^{2}$ per bird (depending on the quality of the floor and group size) effectively banned battery cages. Commercially produced housing systems have to be authorised by the Federal Veterinary Office and Article 5 of the Animal Welfare Act states that authorisation shall only be granted if such systems and installations provide proper living conditions for animals (see also Steiger, 1988; Wechsler et al., 1997). 
In the 10 year transition period that followed, many alternatives to the battery cage system were developed. Those systems, such as enriched cages, colony cages or systems with sloping floors, proved to be unsuccessful and were subsequently not authorised (Federal Veterinary Office, 1993). By contrast, aviary systems proved to be a suitable alternative (Oester and Fröhlich, 1986) and gained acceptance from poultry farmers. Currently, 13 different aviary systems are approved by the Federal Veterinary Office. Whereas $34 \%$ of commercial layers in Switzerland are still kept in deep litter systems, nearly two thirds are housed in aviaries (unpublished data). However, aviaries are not without their problems, especially at the time replacement birds are moved into the system. Depending on the housing conditions during the rearing period, the young birds do not readily use the elevated structures and, if food is provided on raised levels only, some may even starve to death (Oester and Fröhlich, 1988). Sometimes the birds also rest and roost in dense crowds (Fröhlich, 1989) with the consequence of increased agonistic behaviour and disturbed resting behaviour, and occasionally floor eggs may be a problem (Van Horne, 1996). On commercial farms it became clear that aviaries only function optimally when the rearing conditions are appropriate. Replacement stock must have the opportunity to 'learn' about the system during rearing. In contrast to cage systems, there is a need with aviaries to put a strong emphasis on rearing conditions, and so the Federal Veterinary Office commissioned a survey to learn more about how replacement layers were being reared in Switzerland. In addition, the study looked at the prevalence of feather pecking. In aviaries there may be more serious problems with this behaviour than in battery cages (Appleby and Hughes, 1991; Webster, 1994). The behaviour causes serious economic and animal welfare problems because it may result in feather damage, injuries and even the death of birds (Hughes and Duncan, 1972; Allen and Perry, 1975). Feather pecking occurs in both the rearing and laying periods (Hughes and Duncan, 1972; Allen and Perry, 1975) and can be observed as early as the first week of life (Wennrich, 1975). Pecking preferences learned early in life can persist into maturity (Braastad, 1990), and Blokhuis and van der Haar (1989) showed that experiences during rearing may influence pecking behaviour at a later stage. Consequently, it might well be that experiences with feather pecking during rearing influence the occurrence of this behaviour when the birds are in lay. If so, it would emphasise the importance of the rearing period for the performance during lay.

The study included only farms with facilities to raise 500 chicks or more at one time. According to the Federal Statistical Office (data from 1995) this concerned only 155 farms ( $9.7 \%$ of the farms that rear layer replacements), but together they reared 675000 pullets (93.1\% of the laying birds in Switzerland).

In March 1997 all eligible farms were invited to take part in the survey through a letter which had been written in as neutral a manner as possible in order to get a representative sample of farms. Five weeks later a second letter was sent out to increase the number of participants. Finally, 80 farms agreed to be involved in the survey, and between April and December 1997 a total of 66 farms were visited (42.6\% of eligible farms). The necessary data were collected in an interview with the farmer, which took about three hours to conduct and was complemented with an inspection of the rearing house where the latest flock had been reared. The latest flock served as a point of reference for the questions on housing, management and feather pecking.

The following data are presented in a descriptive way, and means are accompanied by $10 \%$ and $90 \%$ quartiles in brackets. The relationship between the 
occurrence of feather pecking and the different rearing conditions is being analysed using epidemiological methods and will be published elsewhere (Huber-Eicher and Audigé, in preparation).

\section{Structure of rearing farms in Switzerland}

Commercial rearing farms in Switzerland are located at a mean altitude of $595(400,850) \mathrm{m}$ above sea level, where the mean temperature is $13.6^{\circ} \mathrm{C}$ in summer and $2.3^{\circ} \mathrm{C}$ in winter and the annual precipitation is $1042 \mathrm{~mm}$. It is usual for the farmers to specialise in poultry and, on two thirds of the farms, pullet rearing and egg production generated more than $90 \%$ of farm income. On only $21.2 \%$ of the farms did income from poultry account for less than $25 \%$ of total income. On $62.2 \%$ of the farms laying stock was kept in addition to rearing birds and, on $46.3 \%$ of those with poultry, the rearing was only for the supply of their own layer replacements. The rearing of replacement layers for home use as well as for supply to others occurred on $48.8 \%$ of these farms, whereas $4.5 \%$ sold all the home reared layers and bought their own replacement layers from other rearing farms.

As well as poultry, cattle (mainly dairy cows) were kept on $42.4 \%$ of farms, pigs on $39.4 \%$, and both pigs and cattle on $21.2 \%$ of farms. Sheep were less common (9.1\% of farms), as were broilers (4.5\%) and other poultry such as turkeys, geese, pheasants or pedigree poultry $(10.6 \%)$. The typical manager of a rearing farm was aged $42.2(29.1,58.3)$ years and, on average, had $16.3(2,37)$ years experience of rearing replacement layers. Half of the managers grew up in a family which was already involved in poultry production and $28.8 \%$ had attended the Swiss Poultry Husbandry School for a total of 27 weeks to become a qualified 'poultry manager'. One in six had attended at least some courses in poultry management, whereas $30.3 \%$ had no specialised poultry training.

\section{Housing}

HOUSING SYSTEM

Rearing layer replacement pullets in the aviary system ( $48.1 \%$ of farms) is now well established, although rearing them in a conventional deep litter system (50.7\% of the available rearing space) is still widespread. 'Aviaries' were defined as systems with elevated platforms and elevated food and drinking facilities. The floor of an aviary was littered except for the droppings pit under the platforms (for more details on aviary systems see STS, 1994; Federal Veterinary Office, 1995; Bessei and Damme, 1998). Surfaces were deemed to be available if there was a clear height of at least $45 \mathrm{~cm}$ above them, if they were at least $30 \mathrm{~cm}$ wide, and if the slope did not exceed $12 \%$. There was an average of $326(182,506) \mathrm{cm}^{2}$ of littered area, and an overall average density of $13.1(9.2,23.1)$ birds per $\mathrm{m}^{2}$ available area. However, because the available surface in aviaries exceeds the floor area, due to the additional tiers, the average density relative to the floor area was $22.5(13.9,32.9)$ birds per $\mathrm{m}^{2}$ with an average flock size of $4002(1910,6180)$ birds.

Deep litter systems were defined as systems with no elevated levels except the usual dropping pits, and with at least a partly littered floor. On average, $73.3 \%(31 \%, 100 \%)$ of the floor area was littered and $670(229,1106) \mathrm{cm}^{2}$ of litter area was available per bird. The mean density was $12.8(7.3,22.1)$ pullets per $\mathrm{m}^{2}$ floor area and the mean flock size was $1814(500,3800)$ birds. It should be noted that in these systems the floor area was equal to the available surface. 


\section{BAD WEATHER RUN}

Certain production labels demand that the pullets have access to an outdoor bad weather area, often called a 'winter garden'. A winter garden was joined on to the poultry house, usually had a concrete floor, and was roofed and littered. The walls were made of wire mesh and the climate was the same as the outdoor climate except for protection from precipitation. At the time of the study, $31.9 \%$ of all layer-type pullets reared in Switzerland had access to a winter garden, which increased the average available area per pullet by $334(140,490) \mathrm{cm}^{2}$. No food was available, but sometimes $(28.6 \%)$ the birds had access to water. The litter was generally shallower than in the indoor area (less than $5 \mathrm{~cm}: 64.3 \% ; 5-10 \mathrm{~cm}$ : $35.7 \%$ ), although additional sand was offered as a dust bath substrate in $21.4 \%$ of the winter gardens. The winter garden was opened for the first time when the pullets were, on average, six $(5.0,9.5)$ weeks old. On $64.3 \%$ of the farms with a winter garden it stayed open throughout the day, while on the other farms it was available in the afternoon only. Winter gardens were well used by the birds; on $71.4 \%$ of the farms they were typically used by $25-50 \%$ of the animals, but fewer birds used them when the weather was cold and windy. However, most farmers $(85.7 \%)$ closed the winter garden only when temperatures were below zero. A free range area was not usually provided during the rearing of layer-type pullets

\section{LIGHT}

Most pullets $(73 \%)$ were reared with access to daylight, with the aviary and deep litter systems having similar proportions $(73.0 \%$ and $73.6 \%$, respectively). Barns without daylight were usually illuminated with incandescent lamps $(70.8 \%)$, whereas others $(20.1 \%)$ used fluorescent tubes and a few $(8.3 \%)$ used both types of lamp. Light intensity in artificially illuminated barns was $5.4(1.6,15.6)$ lux. It was measured at bird height and in the area where the birds were active, and the mean was calculated from measurements taken at six specific points (up, down, left, right, front and rear).

\section{PERCHES}

Elevated perches (i.e. perches at a minimum height of $35 \mathrm{~cm}$ above the underlying surface) were provided on half of the farms, with an average of $8.4(2.3,15.3) \mathrm{cm}$ of perch length per individual. Where provided, the perches were available from week 1 on $59.4 \%$ of farms and by week 4 on $81.2 \%$ of the farms. Perches, but not elevated ones, were found on $43.7 \%$ of farms, and these provided $10.2(3.9,18.2) \mathrm{cm}$ per bird. Perches were not provided on $6.2 \%$ of the farms.

\section{LITTER}

All the pullets had access to litter. Wood shavings were often used as litter $(48.4 \%)$, but long-cut straw $(15.6 \%)$ or chopped straw $(10.9 \%)$ was also used and, on $14.1 \%$ of farms, the litter comprised a mixture of wood shavings and straw. Sometimes $(4.7 \%)$ the wood shavings were mixed with sawdust and, in a very few cases, the litter consisted entirely of sawdust or peat ( $1.6 \%$ each). The depth of the litter was seldom less than $5 \mathrm{~cm}$ (6.4\%), but mostly between 5 and $10 \mathrm{~cm}(65.1 \%)$. No farm offered additional sand as a dust bath substrate in the indoor area.

\section{FEEDING AND DRINKING FACILITIES}

Most farms (73.4\%) used an automatic chain feeder, where $3.5(2.4,4.9)$ linear $\mathrm{cm}$ of trough (accessible from both sides) was provided per pullet. Round feeders were used on $20.3 \%$ of farms, with a mean feeding space of $2.5(1.1,4.5) \mathrm{cm}$ per 
pullet, whereas the remaining farms used a combination of both automatic chain feeders and round feeders. Nipple drinkers were used on $82.2 \%$ of farms and it was usual for farmers to provide more than the one nipple per 15 birds recommended in the Animal Welfare Regulations. Drinking facilities that offered an open water surface were used on $15.6 \%$ of farms. In general these were cup drinkers, but sometimes round automatic waterers or automatic water troughs were installed.

\section{Management}

\section{GENERAL PROCEDURE}

A third of the birds were beak-trimmed at the hatchery and a further $11.0 \%$ were beak-trimmed at 7-10 days of age. More than half $(56 \%)$ were generally not beak-trimmed, except in rare cases when beak-trimming was conducted at an older age to reduce feather pecking. The chicks were delivered to the farms on the day of hatch or, at the latest, the day following hatch in specialised cardboard boxes $(50 \times 60 \times 14.5 \mathrm{~cm})$ which held a total of 100 chicks divided among four compartments. The average transport time to the farm was two $(0.5,3.0)$ hours and was always by road transport (59.4\% of which was air conditioned). During the first two weeks the chicks in deep litter systems were kept in large rings constructed of cardboard (about $50 \mathrm{~cm}$ high) and, in aviaries, they were confined to the bottom tier. In this way it was guaranteed that the chicks stayed close to feed, water and heat. The mean stocking density during this starting phase was $66(34,106)$ birds per $\mathrm{m}^{2}$ (deep litter 58 birds per $\mathrm{m}^{2}$, aviaries 72 birds per $\mathrm{m}^{2}$ ) and the average group size was 1701 (421,3193) birds (deep litter 1251, aviaries 2377). In most cases the same litter material was used in the partitioned off area as in the rest of the pen. On $32.8 \%$ of the farms (with one exception, all with aviaries) the area was not littered but was made of mesh (wire or synthetic material) or strong paper that could not be pecked by the chicks. The starting phase was very labour intensive because water and feed were distributed manually. Water was provided in small chick drinkers in addition to the nipple or cup drinker system, and feed was provided on trays (diameter $30-45 \mathrm{~cm}$ ) or on the cut off base of the boxes that were used to deliver the chicks. In this way an additional feeding area of $22.0(5.5,41.6) \mathrm{cm}^{2}$ per chick was created, which was used by the chicks for feeding, scratching and dust bathing. In deep litter systems only the partitioned off area was heated, in contrast to aviaries where usually the whole pen had to be heated because the distance between the tiers was too small to install a heater. The temperature regime recommended by the chick supplier was not strictly followed but, more importantly, it was decided by the experience of the farmer and observations of the chicks' behaviour. The temperature was said to be right when the resting chicks were scattered loosely around the edge of the heat source, and this was achieved by varying the distance between the heat source and the floor and by making the cardboard rings large enough to enable the chicks to choose areas where the temperature was most convenient for them. These possibilities usually did not exist in aviaries. As a consequence, the regulation of the temperature in the starting phase was more delicate in aviaries than in deep litter systems. This and the higher density may be one of the reasons why the partition was removed roughly two days earlier in aviaries than in deep litter systems (days 15 and 17 , respectively). The lighting regimes recommended by the chick supplier were followed closely, with differences existing only in the first few days. On most of the farms $(80.3 \%$ ) continuous illumination was provided for the first 
24 hours only, whereas half of the farms continued it for a further 24 hours and one third even up to 72 hours. Few $(10.6 \%)$ left the lights on for 96 hours or longer. Bird management was most labour intensive during the first week, with farmers making an average of $4.3(2,7.5)$ checks a day and the daily work taking $100(35,180)$ minutes to be completed. In the second week there were $3.5(2,6)$ checks and working time was $71(30,135)$ minutes, whereas in the third week checks were reduced to $2.9(2,4.5)$ and the work time was down to $52(15,120)$ minutes. From the fourth week until the birds were moved to the laying house at between 16 and 19 weeks the number of checks and the time spent on daily duties stayed much the same at $2.2(1,3.5)$ and $31(10,60)$ minutes respectively.

\section{FEED AND FEEDING}

Principally the rearing farms used diets, in meal form, produced by large commercial milling companies, although crumbed diets were sometimes used during the first few days. Pelleted feed was not used in the rearing period on any farm. During the rearing phase there were usually two $(51.6 \%)$ or three (35.9\%) different feed formulations. Raw materials produced on the farm were not used in diet formulation. Whole grain and grit were sometimes provided in addition to the feed $(7.8 \%$ and $17.2 \%$, respectively). The feeder chain usually ran automatically from the fourth week onwards for $5.6(3,8)$ times a day with a total running time of $47(17,77)$ minutes, and on two out of three farms the feeding times were distributed evenly through the day.

\section{VACCINATION, PARASITES AND MICE}

During the rearing phase all farms vaccinated once against infectious avian encephalomyelitis and two or three times against infectious bronchitis. The majority of farms also vaccinated two or three times against infectious bursal disease. The vaccines were administered via the drinking water and in strict accordance with the recommendations of the hatchery. There were vast differences in the time when vaccinations were applied and in how many times they were repeated; however, it was difficult to justify these differences on veterinary grounds ( $R$. Hoop, Institute for Veterinary Bacteriology, University of Zürich, personal communication). It was not possible to collect data on vaccination against Marek's disease because it is done at the hatchery and often the farmers did not know about it, but according to the information provided by several hatcheries the chicks were regularly vaccinated. Coccidiostats were added to the feed generally up to week $12(8,18)$. The programme was principally influenced by the different production labels which tolerated coccidiostats in the feed only up to 12 weeks. Despite the use of coccidiostats, $12.5 \%$ of the farms reported an outbreak of coccidiosis when the chicks were about seven $(2,12)$ weeks old. Red mite (Dermanyssus gallinae) and chewing lice (Mallophaga) were observed by $15.6 \%$ and $1.6 \%$ of the farmers respectively, and on $4.7 \%$ of farms 'beetles' and 'larvae' (probably Alphitobius diaperinus) were found in the litter. Mice, which were observed in almost half the units, were present 2.5 times more frequently in deep litter systems with droppings pits than in deep litter systems without such pits or in aviaries.

\section{Feather pecking}

Whether feather pecking was or was not considered to be a problem in a specific flock depended on the criteria used for its assessment. Whilst one farmer may 
have thought that his flock had a serious problem with feather pecking when he observed feather damage, another thought that there was only a problem after he observed losses due to feather pecking. Accordingly, the farmer was initially asked which criterion was used to decide whether there was feather pecking and then whether the problem was serious enough to take measures against it.

\section{CRITERIA FOR THE OCCURRENCE OF FEATHER PECKING}

A third of the farmers thought that feather pecking was serious enough to take action when they observed individual birds pecking the feathers of others, whereas half of the farmers used the occurrence of feather damage, like broken feathers or damaged vanes, as the criterion. A further $7.6 \%$ did not take measures until they observed naked areas, whilst $12.1 \%$ did not think that there was a problem with feather pecking in a flock until they observed injuries or losses.

\section{PREVALENCE OF FEATHER PECKING}

Taking the status of the latest flock that was reared on the farm, $37.5 \%$ of the farmers judged their own flock as having problems with feather pecking according to the above criteria. There were two distinct times when feather pecking initially occurred in a flock (Figure 1). Problems with feather pecking, which were not observed before three weeks of age and did not start later than 12 weeks, often started in weeks 3 or 4 or between weeks 7 and 10. Problems with feather pecking were found in $40.0 \%$ of the aviaries and in $35.9 \%$ of the deep litter systems; however, the difference was not statistically significant $\left(\chi^{2}=0.11, \mathrm{n} . \mathrm{s}\right.$. $)$. Feather pecking did not result in an increase in losses during the rearing period which averaged $2.7 \%(0.3 \%, 6.3 \%)$ and $2.5 \%(0.9 \%, 5.7 \%)$ in flocks with or without feather pecking, respectively.

MEASURES TO REDUCE FEATHER PECKING

Once feather pecking was acknowledged to be a problem in a flock, $84.0 \%$ of the farmers reduced light intensity and/or covered the windows to reduce

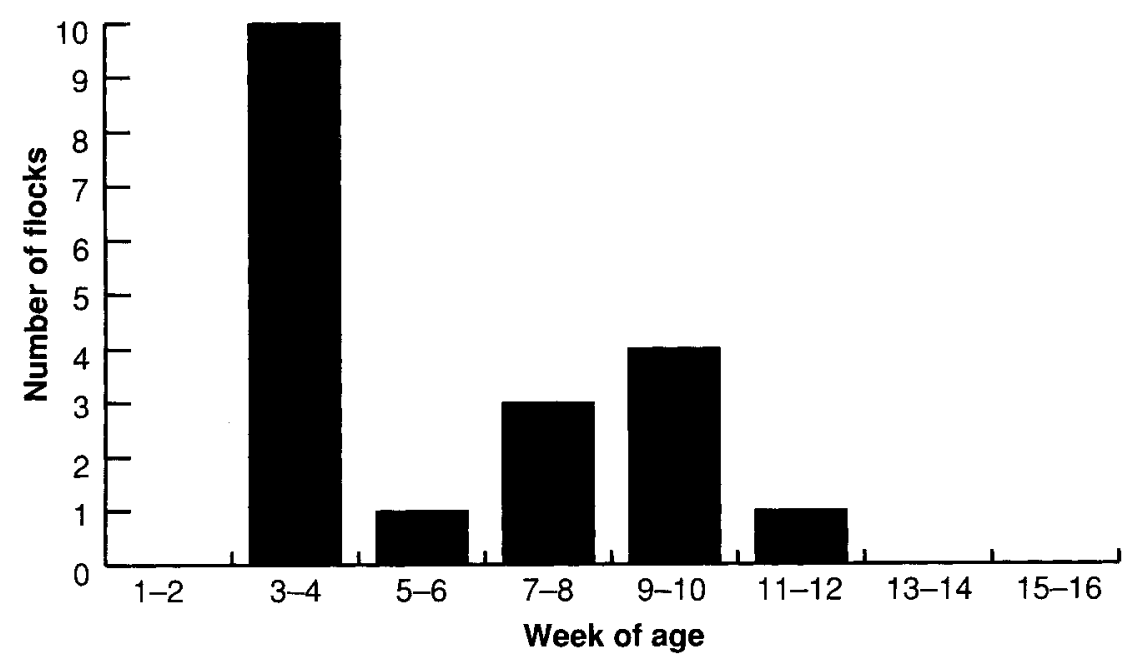

Figure 1 Age at first occurrence of feather pecking problems during the rearing of layer replacements. 
daylight. A second widely used measure $(31.0 \%)$ was the provision of straw to occupy the chicks, and sometimes $(8.5 \%)$ grains were scattered onto the litter to increase foraging behaviour. Other measures occasionally used to keep the birds better occupied or to distract their attention from the feathers of the other birds included the provision of red plastic buckets, having a radio on, or different persons walking frequently through the flock over a period of several days. Further measures used to improve the environment included moistening the litter to reduce dust levels and lower the temperature and increasing the ventilation rate. In addition, occasionally the birds were beak-trimmed, the winter garden was kept closed or the injuries were treated with tar to prevent the chicks from pecking at them. Usually the farmers continued the measures for the rest of the rearing period but, where they did not, a second outbreak of feather pecking was observed in $25.0 \%$ of cases. The measures taken were judged by $91.6 \%$ of the farmers to have had an influential effect on the reduction of feather pecking.

\section{Potential management problems of aviaries}

The management procedures used when rearing pullets in aviaries were different from those used in deep litter and these had produced otherwise unseen problems. It was especially true in the initial phase. The chicks were confined to the lowest tier of the aviary for the first two weeks, but the enclosure was opened up when some chicks started to jump over it. The feeding and drinking facilities were arranged over the tiers, but because the level of the bottom tier was usually at least $45 \mathrm{~cm}$ above floor level, some birds that had jumped down onto the litter were unable to get back on to the tier. The farmer therefore had to lift the remaining chicks from the litter area back onto the tier each evening for several days. The problem could be reduced by providing the chicks with little ramps that led up to the tier.

The absence of litter in aviaries during the first few weeks of life also posed a potential problem and it has been reported by Johnsen et al. (1998) that this may be a possible trigger for feather pecking. In our study more than one third of the farmers reported problems with this behaviour. However, the prevalence of feather pecking in aviaries was not significantly different from that in deep litter systems. It should therefore be possible to further reduce it by giving access to litter in the first two weeks so that feather pecking would occur even less often in aviaries than in deep litter systems. Alternatively, these difficulties could be avoided if the birds were brooded on the littered area of the aviaries rather than on the lowest tier. Whilst this would require the installation of additional feeding and drinking facilities for a period of two weeks, the extra resources involved might be a good investment in terms of better subsequent performance.

\section{Acknowledgements}

I am grateful to the Federal Veterinary Office of Switzerland for their financial support of the research project (No. 2.97.4) and to Hans Oester and Ernst Fröhlich who made valuable comments on the manuscript.

\section{References}

ALLEN, J. and PERRY, G. C. (1975) Feather pecking and cannibalism in a caged layer flock. British Poultry Science 16: 441-451 
APPLEBY, M. C. and HUGHES, B. O. (1991) Welfare of laying hens in cages and alternative systems: environmental, physical and behavioural aspects. World's Poultry Science Journal 47: 109-128

BESSEI, W. and DAMME, K. (1998) Neue Verfahren fur die Legehennenhaltung, KTBL-Schrift 378. KTBL, Darmstadt

BLOKHUIS, H. J. and VAN DER HAAR, J. W. (1989) Effects of floor type during rearing and of beak trimming on ground pecking and feather pecking in laying hens. Applied Animal Behaviour Science 22: $359-369$

BRAASTAD, B.O. (1990) Effects on behaviour and plumage of a key-stimuli floor and a perch in triple cages for laying hens. Applied Animal Behaviour Science 27: 127-139

FRÖHLICH, E. K. F. (1989) Effects of the behaviour related to rearing systems: the possible extent of adaptation of chicks to restrictive rearing system and the consequences of such rearing environments on the resting behaviour and self maintenance of laying hens. Proceedings of the 3rd European Symposium on Poultry Welfare 1989, Tours, France, pp. 137-148

FEDERAL VETERINARY OFFICE (1993) Kurzbeschreibung der für den Verkauf nicht zugelassenen Haltungssysteme für Legehennen. Information Tierschutz, 800.107.06, Bundesamt für Veterinärwesen, $\mathrm{CH}-3097$ Liebefeld-Bern

FEDERAL VETERINARY OFFICE (1995) Kurzbeschreibung der in der Schweiz verfüjgbaren, serienmässig hergestellten Haltungssysteme für Legehennen. Information Tierschutz, 800.107.04, Bundesamt für Veterinärwesen, $\mathrm{CH}-3097$ Liebefeld-Bern

HUGHES, B. O. and DUNCAN, I. J. H. (1972) The influence of strain and environmental factors upon feather pecking and cannibalism in fowls. British Poultry Science 13: 525-547

JOHNSEN, P. F., VESTERGAARD, K. S. and NORGAARD-NIELSEN, G. (1998) Influence of early rearing conditions on the development of feather pecking and cannibalism in domestic fowl. Applied Animal Behaviour Science 60: 25-41

OESTER, H. and FRÖHLICH, E. (1986) Die Beurteilung der Tiergerechtheit der neuen Haltungssysteme für Legehennen im Rahmen der Tierschutzgesetzgebung. Schweizer Archiv für Tierheilkunde 128: $521-534$

OESTER, H. and FRÖHLICH, E. (1988) New housing system for laying hens in Switzerland. Proceedings of the 6th International Congress on Animal Hygiene, Skara, Sweden, pp. 709-712

STEIGER, A. (1988) Swiss Animal Welfare Legislation and the examination of housing systems. Proceedings of the Fourth European Conference on the Protection of Farm Animals 1988, Brussels, Belgium, pp. 89-92

STS SWISS SOCIETY FOR THE PROTECTION OF ANIMALS (Ed.) (1994) Laying hens: 12 years of Experience with New Husbandry Systems in Switzerland. Bern, Kümmerli \& Frey AG

VAN HORNE, P. L. (1996) Production and economic results of commercial flocks with white layers in aviary systems and battery cages. British Poultry Science 37: 255-261

WEBSTER, J. (1994) Animal Welfare: A Cool Eye Towards Eden. Blackwell Science, Oxford

WECHSLER, B., FRÖHLICH, E., OESTER, H., OSWALD, T., TROXLER, J., WEBER, R. and SCHMID, H. (1997) The contribution of applied ethology in judging animal welfare in farm animal housing. Applied Animal Behaviour Science 53: 33-43

WENNRICH, G. (1975) Studien zum Verhalten verschiedener Hybrid-Herkünfte von Haushühnern (Gallus domesticus) in Bodenintensivhaltung mit besonderer Berücksichtigung des aggressiven Verhaltens sowie des Federpickens und des Kannibalismus. 5. Mitteilung: Verhaltensweisen des Federpickens. Archiv für Geflügelkunde 39: 37-44 